\title{
INDEX OF VOLUME 55
}

\section{INDEX OF ABSTRACTS}

Subjects:

Algebra and Theory of Numbers, $39,55,61,271,510,522,667,686,707,715,871$, 1042.

Analysis, 41, 55, 66, 279, 514, 524, 669, 689, 708, 716, 871, 1053.

Applied Mathematics, 48, 57, 69, 291, 519, 525, 673, 698, 710, 718, 1068.

Geometry, 50, 58, 70, 297, 526, 674, 699, 712, 719, 1072.

Logic and Foundations, 50, 70, 298, 526, 702, 875, 1074.

Numerical and Graphical Methods, 71.

Statistics and Probability, 50, 71, 300, 520, 676, 702, 713, 1075.

Topology, 52, 58, 301, 521, 527, 676, 703, 713, 875, 1078.

Authors:

Abbott, J. C., 1042; Abramowitz, M., 48, 291, 698; Aczel, J., 689; Albert, A. A., 686; Ames, D. B., 514; Anderson, R. D., 301, 301, 1078; Andree, R. V., 1043; Apostol, T. M., 715; Aronszajn, N., 279.

Bagemihl, F., 279; Barlaz, J., 1053; Barnett, I. A., 1043; Bateman, P. T., 686, 686, 686, 1043; Beckenbach, E. F., 41, 280, 1053; Becker, H. W., 69, 718, 718, 1192; Beesley, E. M., 716; Begle, E. G., 58; Bell, J. H., 1044; Bell, P. O., 712, 712; Bellman, R., 510, 510, 510, 511, 686; Benac, T. J., 1042; Bergman, S., 515, 515, 515, 515, 1192; Bernhart, A., 707; Bernstein, F., 669; Bers, L., 516, 690, 1053; Bing, R. H., 58, 713, 1078; Birkhoff, G., 41, 42, 48, 871; Blakers, A. L., 703; Blankinship, W. A., 703; Blau, J. H., 704; Block, H. D., 280, 1053; Blumberg, H., 298; Blumen, I., 676; Blumenthal, L. M., 271; Boas, R. P., 55; Bochner, S., 690; Boldyreff, A. W., 1044; Boothby, W. M., 690; Bott, R., 291; Bourgin, D. G., 690, 704; Brauer, A. T., 272, 667; Brown, B., 272; Buchi, J. R., 1044; Buck, R. C., 687, 687.

Cairns, S. S., 301; Calabi, E., 280; Calderón, A. P., 1054, 1054; Calkin, J. W., 280; Cameron, R. H., 281; Carlitz, L., 272, 272, 667, 667, 687, 1044; Carruth, P. W., 42; Cashwell, E. D., 708; Castellani, M., 1075; Cesari, L., 716; Chandrasekharan, K., 690; Chang, S. H., 871, 872, 872, 872; Charnes, A., 704; Chatland, H., 55; Chen, Y. W., 292; Chernoff, H., 1075; Cherry, T. M., 516; Chin, L. H., 61; Chowla, S., 273, 273, 273, 273, 274, 511, 511, 686, 686, 686; Chung, K. L., 702, 1076; Civin, P., 66; Clark, R. A., 673; Clarke, F. M., 274, 274, 707; Coburn, N., 1068; Cohen, A. C., 676; Cohen, C., 512, 698; Cohen, E., 274; Cohen, H. J., 713; Cohen, L. W., 52, 56, 281; Cohen, H., 48, 274, 522; Conrad, K. L., 1069; Copeland, A. H., 698; Court, N. A., 297, 1072; Cowling, V. F., 281, 873; Craig, H. V., 56, 674; Curry, H. B. 299, 299, 299.

Darling, D. A., 300, 702, 703; Davenport, H., 55; Day, M. M., 1054, 1054; DeCicco, J., 50, 526, 526, 699, 700, 712; Dekker, D. B., 719; Dietrich, V. E., 55; Dilworth, R. P., 62, 63, 301, 1079; Dolciani, M. P., 39, 687; Dolph, C. L., 713, 1076; Dowker, C. H., 301; Doyle, T. C., 519; Dresden, M., 1069; Dresher, M., 275; Dubisch, R., 715, 1045; Duffin, R. J., 282, 282, 291, 292; Dvoretzky, A., 42, 50, 280, 1055.

Eberlein, W. F., 292, 1055; Eichler, M. M. E., 282; Elliott, H. M., 43, 43, 47, 283, 874; Ellis, D. O., 271; Engel, J. H., 707; Erdös, P., 1076; Estill, M. E., 875; Evans, G. C., 1055; Everett, C. J., 51, 51, 51; Ewing, G. M., 709.

Fan, K., 59, 59; Farnell, A. B., 1059; Farrell, O. J., 691, 691; Federer, H., 688; Fejer, L., 1055; Ficken, F. A., 674; Fine, N. J., 275; Finkbeiner, D. T., 62; Fisher, R. C., 712; Floyd, E. E., 704; Forsythe, G. E., 66, 293; Fort, M. K., 59, 59, 527; Foster, A. L., 39; Fox, R. H., 52, 276, 512, 521, 704; Frame, J. S., 1045; Frank, E., 
283; Freilich, G., 691; Freundlich, M. R., 302; Fuchs, W. H. J., 283; Fullerton, R. E., 302.

Gadsden, C. P., 669; Galbraith, A. S., 43; Gale, D., 512, 512, 688, 1045; Garabedian, P. R., 67; Gentry, I. C., 676; Germond, H. H., 1076; Gilbarg, D., 525; Givens, W., 1046; Gleason, A. M., 283, 1079; Goffman, C., 52, 56, 281; Goodman, A. W., 284; Goldberg, M., 297; Goodner, D. B., 1056; Gorciu, V. G., 302; Goss, R. N., 710, 1069; Gottschalk, W. H., 1079; Graves, L. M., 1056; Green, J. W., 284, 302, 720; Grove, V. G., 58, 1073; Guenther, P. E., 673; Gustin, W., 284, 302, 524, 1056; Guy, W. T., 56.

Hall, M., 276, 300; Hamilton, O. H., 714; Harary, F., 55, 276, 276, 277; Harrold, O. G., 302, 677; Heins, A. E., 698; Helsel, R. G., 284; Herstein, I. N., 523, 707; Herzog, F., 1056; Hestenes, M. R., 67; Hewitt, E., 303, 1057, 1057; Higman, G., 667; Hille, E., 1058, 1058; Hirschman, I. I., 516, 873; Hoel, P. G., 1076; Hoffman, A. J., 297; Hopf, E., 1069; Horn, A., 70; Hostinsky, L. A., 1046; Hua, L. K., 1046, 1046, 1047, 1047, 1047; Huff, G. B., 277, 674; Hughes, H. K., 709; Hutcherson, W. R., 1073; Hutchinson, L. C., 277; Hyman, M. A., 284.

Ingram, W. H., 692; Isaacson, E., 48.

Jacobson, F. D., 513; Jacobson, N., 513, 1047; James, R. D., 717; Jehle, H., 293; Jenkins, J. A., 285, 516, 873; Jerison, M., 1079; Jones, B. W., 277; Jónsson, B., 688.

Kac, M., 703; Kahal, R., 1070; Kakutani, S., 1058, 1059; Kaplan, Samuel, 677; Kaplan, Sidney, 519; Kaplansky, I., 278, 513; Karlin, M., 516; Karlin, S., 524, 717; Kasner, E., 50, 526, 526, 699, 700, 700; Katz, L., 1077; Keesee, J. W., 677; Klee, V. L., 44, 44, 44, 669, 670, 670, 670, 670; Kober, H., 692; Koopman, B. O., 520; Krzywoblocki, M. Z., 57, 525, 711; Kuhn, Harold W., 512, 688, 1045; van der Kulk, W., 700.

Lakness, R. M., 67; Lanczos, C., 717; Lane, R. E., 285, 1059; Langenhop, C. E., 1059 ; Langer, R. E., 285, 294 ; Leavitt, W. G., 709; Lehmer, D. H., 715, 1047; Lehmer, E., 62; Lehner, J., 40, 286, 1060; Leighton, W., 718, 1060; Lepson, B., 1048; Leutert, W., 44; LeVeque, W. J., 688, 688; Levine, J., 675, 701; Levinson, N., 517, 517, 692, 693, 693, 693; Levit, R. J., 667; Levitzki, J., 513; Lieblein, J., 1077; Lin, C. C., 49, 49; Linial, S., 50; Loomis, L. H., 517; Lorch, E. R., 693; Lyndon, R. C., 513.

McCoy, N. H., 272; McKinsey, J. C. C., 278; McLaughlin, J., 63; McShane, E. J., 49, 303, 873; Macintyre, S. S., 44; Mackey, G. W., 286, 286, 694; MacLane, G. R., 287; Macon, N., 272; Magnus, W., 1048; Malin, H., 69; Mandelbrojt, S., 287; Mann, H. B., 276; Maple, C. G., 294; Martin, M. H., 673, 1070; Martin, W. T., 281; Massey, W. S., 303, 703, 1080; Mautner, F. I., 40, 52, 287; Mendel, C. W., 1043; Mersman, W. A., 718; Metropolis, N., 670; Min, S. H., 517; Mitchell, B. E., 675, 1073; Mitchell, J. M., 524, 709; Mittleman, D., 700, 701; Moise, E. E., 527; Montgomery, D., 60; Moore, C. N., 45, 287; Moore, E. F., 694; Morrey, C. B., 1060; Morrison, W. J. 1077; Mostowski, A., 65, 65, 1192; Motzkin, T. S., 40, 1073; Myers, S. B., 1080.

Nachbin, L., 40, 45, 873; Nehari, Z., 525; Nemenyi, P. F., 1070; Nesbeda, P., 671; Neumann, B. H., 667; Neumann, H., 667; Neustadter, S. F., 68; Nicholson, G. E., 676; Nickerson, H. K., 1061, 1061; Nikodým, O. M., 288, 1080, 1080; Niven, I., 715; Northam, J. I., 713; Norton, D. A., 1048; Novak, I. L., 300, 702.

O'Brien, G., 519; O'Donnell, R. E., 1061; Ostrowski, A. M., 719, 1061; Oxtoby, J. C., 694.

Pall, G., 278, 689; Parker, W. V., 668, 871; Parrish, H. C., 288; Payne, L. E., 1071; Peiser, A. M., 695; Perkins, F. W., 695; Perlis, S., 41, 1045; Peters, G. O., 671; Phillips, R. S., 69, 719; Pinney, E., 69, 719; Piranian, B., 1062; Piranian, G., 1056, 1062; Pitcher, E., 45; Pitman, E. J. G., 676; Pollard, H., 703; Polya, G., 294, 294; Porcelli, P., 689; Post, E. L., 50; Price, C. M., 523. 
Rademacher, H., 695; Rado, T., 1062; Ramanathan, K. G., 273, 523, 668, 1049; Ratner, L. T., 1080; Rauch, H. E., 518; Rauch, L. L., 1062; Reade, M. O., 288, 289, 297; Rechard, O. W., 56; Regan, F., 1063; Reichelderfer, P. V., 1062; Reid, W. T., 57, 1049, 1063; Reissner, E., 49, 295, 295, 519, 673, 674; Reynolds, C. N., 705, 1081; Ribeiro, H., 278; Rickart, C. E., 279, 279, 1047, 1049, 1050; Riggs, L. G., 1063; Ritt, J. F., 695; Ritter, E. K., 1063; Ritter, I. F., 519, Robbins, H. E., 676; Robinson, J., 70; Robinson, L. V., 289, 671; Robinson, R. M., 1050; Rogosinski, W. W., 1064; Room, T. G., 298; Rosenbloom, P. C., 46, 289, 689; Rosenthal, A., 55; Rosser, J. B., 875, 1050; Roth, W. E., 1050, 1050; Rothe, J. C., 874; Rubin, H., 1050, 1064, 1064; Rudin, W., 668, 671, 1064; Rust, C., 1063; Rutledge, W. A., 1046; Ryser, H. J., 511, 511,871 .

Salzer, H. E., 41, 57, 295; Sard, A., 695; Schaeffer, A. C., 282, 1065; Schaerf, H. M., 1065, 1065, 1065, 1066, 1066; Schafer, R. D., 689; Schatten, R., 289, 1066; Scherk, P., 1051; Schiffer, M. M., 515, 515, 515, 515, 1192; Schoenberg, I. J., 695, 696; Schoenfeld, L., 525; Schwartz, H. M., 290, 518, 672; Schweigert, G. E., 304; Schweitzer, A. R., 526, 527, 1074, 1074; Scott, W. T., 1063; Segal, I. E., 46, 46, 57; Seidel, W., 43, 280; Seth, B. R., 295, 711, 1071; Sewell, W. E., 47; Shanks, D., 696; Shapley, L. S., 717; Sherman, J., 1077; Sherman, S., 290, 514; Silverman, E., 518; Simmons, H. A., 523; Sinclair, A., 1066; Sips, R., 47; Smiley, M. F., 524, 1051; Smith, H. L., 1067; Snapper, E., 300; Snyder, W. S., 672; Specht, E. J., 1067; Spencer, D. E., 1071; Springer, C. E., 710; Springer, G. E., 290; Steel, R. G. D., 707; Steinberg, R., 514; Stephens, C. F., 697, 874; Stone, A. H., 52; Strehler, A. F., 708; Strodt, W., 697; Studley, D. M., 711, 1074, 1078; Sugar, A. C., 70, 296; Sumner, D. B., 697; Szasz, O., 47, 280, 290, 1067; Szegó, G., 294, 1055, 1064; Szekeres, G., 689; Szmielew, W., 65, $1075,1192$.

Tarski, A., 61, 63, 63, 64, 64, 65, 1051, 1075, 1192; Taylor, A. E., 68; Thielman, H. P., 291, 710, 1067; Thomas, G. B., 673; Thomas, J. M., 675; Thompson, F. B., 66; Thorne, C. J., 69, 71; Thrall, R. M., 1052; Todd, J., 1071; Tompkins, C., 520; Tornheim, L., 1052; Townsend, B. B., 674; Truesdell, C. A., 296, 699, 1072; Tsien, H. S., 49; Tucker, A. W., 512, 688, 1045; Turán, P., 274.

Ulam, S. M., 51, 51, 51, 670; Ullman, J. L., 291, 1067; Utz, W. R., 298, 1081.

Valentine, F. A., 720; Van Tuyl, A. H., 699, 1070; Vaught, R. L., 716; Vinograde B., 708.

Wade, L. I., 668; Walker, G. L., 41; Wall, H. S., 285; Walsh, J. E., 1078; Walsh, J. L., 43, 47, 874; Wang, H., 875; Ward, J. A., 669; Ward, M., 716; Weinstein, A., 294, 520, 699; White, P. A., 1081; Whitehead, G. W., 521; Whiteman, A.L., 68, 71; Whitney, A. M., 696; Whyburn, G. T., 60, 60, 304, 304, 305, 705; Whyburn, W. M., 672; Widder, D. V., 874; Wilcox, L. R., 1052; Wolfgang, W. G., 701, 702; Woodbury, M. A., 713, 1076.

Yood, B., 673.

Zeichner, A., 296; Zippen, L., 521; Zorn, M. A., 300; Zuckerman, H. S., 1057, 1057; Zygmund, A., 1068.

\section{INDEX OF REPORTS OF MEETINGS AND MISCELLANEOUS ARTICLES}

Churchill, R. V., and Youngs, J. W. T. Third Symposium on Applied Mathematics, 861. Davenport, H. See Littlewood, J. E.

Dresden, A. Report of Committee on Aid to Devastated Libraries, 1.

Green, J. W. Reports of Meetings of the American Mathematical Society: November Meeting in Los Angeles, 61; A pril Meeting in Stanford University, 714; Summer Meeting in Boulder, 1035. 
Hardy, G. H. See Wiener, N.

Hollcroft, T R. Reports of Meetings of the American Mathematical Society: October Meeting in New York, 38; February Meeting in New York, 509; April Meeting in Durham, 666; April Meeting in Philadelphia, 678.

Kline, J. R. Memoirs of the American Mathematical Society, 1013.

Littlewood, J. E., P6lya, G., Mordell, L. J., Titchmarsh, E. C., Davenport, H., and Wiener, N. Two statements concerning the article on G. H. Hardy, 1082.

Mordell, L. J. See Littlewood, J. E.

Pblya, G. See Littlewood J. E.

Titchmarsh, E. C., See Littlewood, J. E.

Wiener, N. Godfrey Harold Hardy, 1877-1947, 72.

- See Littlewood, L. J.

Youngs, J. W. T. Reports of meetings of the American Mathematical Society: November Meeting in Chicago, 54; Annual Meeting of the Society, 261; February Meeting in Chicago, 522; April Meeting in Lawrence, 706.

- See Churchill, R. V.

\section{INDEX OF BOOK REVIEWS}

Allendoerfer, C. B. See Coxeter, H. S. M.

Bass, J. Les méthodes modernes du calcul des probabilités et leur application au problème de la turbulence. M. Loève, 864.

Behari, R. The differential geometry of ruled surfaces. J. DeCicco, 313.

Bochner, S. See Hille, E.

Cambi, E. Eleven and fifteen-place tables of Bessel functions of the first kind, to all significant orders. E. R. Lorch, 78.

Coxeter, H. S. M. Regular polytopes. C. B. Allendoerfer, 721.

- See Hodge, W. V. D.

DeCicco, J. See Behari, R.

Dieudonné, J. Sur les groupes classiques. E. R. Kolchin, 317.

Federer, H. See Hahn, H.

Fort, T. Finite differences and difference equations in the real domain. W. Strodt, 312.

Hahn, H., and Rosenthal, A. Set functions. H. Federer, 316.

Hlavaty, V. See Vranceanu, G.

Hille, E. Functional analysis and semi-groups. S. Bochner, 528.

Hodge, W. V. D., and Pedoe D. Methods of algebraic geometry. H. S. M. Coxeter 315.

Householder, A. S. See Rashevsky, N.

Kolchin, E. R. See Dieudonné, J.

Landahl, H. D. See Luneburg, R. K.

Loève, M. See Bass, J.

Lorch, E. R. See Cambi, E., Parke, N. G., Tables.

Luneburg, R. K. Mathematical analysis of binocular vision. H. D. Landahl, 866.

McCoy, N. H. Rings and ideals. C. C. MacDuffee, 864.

MacDuffee, C. C. See McCoy, N. H.

Parke, N. G. Guide to the literature of mathematics and physics including related works on engineering science. E. R. Lorch, 78.

Pedoe, D. See Hodge, W. V. D.

Rashevsky, N. Mathematical theory of human relations. An approach to a mathematical biology of social phenomena. A. S. Householder, 722.

Robinson, G. de B. See Rutherford, D. E.

Rosenthal, A. See Hahn, H.

Rutherford, D. E. Substitutional analysis. G. de B. Robinson, 1085. 
Strodt, W. See Fort, T.

Tables of spherical Bessel functions. Vol. 2, E. R. Lorch, 78.

Tables of the Bessel functions of the first kind of orders four, five, six, seven, eight, and nine.

E. R. Lorch, 79.

Tables of Bessel functions of fractional order. Vol. 1. E. R. Lorch, 79.

Thron, W. J. See Wall, H. S.

Vranceanu, G. Leçons de géométrie différentielle, V. Hlavaty, 867.

Wall, H. S. Analytic theory of continued fractions. W. J. Thron, 1083.

\section{INDEX OF ADDRESSES ${ }^{1}$}

Bergman, S., 510.

Besicovitch, A. S., 263.

Busemann, H., 61.

Cesari, L., 263.

Eilenberg, S. Topological methods in abstract algebra. Cohomology theory of groups, 3.

Halmos, P. R., 54.

- Measurable transformations, 1015.

Hedlund, G. A., 1036.

Hestenes, M. R., 714.

Hille, E., 263.

Householder, A. S., 706.

James, R. D. Recent progress in the Goldbach problem, 246.

Jessen, B., 1036.

Jones, F. B., 1036.

Kac, M., 263.

- Probability methods in some problems of analysis and number theory, 641.

Mackey, G. W., 679.

MacLane, S., 54.

Mickle, E. J., 706.

Myers, S. B., 522.

Reidemeister, K. W., 679.

Reissner, E. Boundary value problems in aerodynamics of lifting surfaces in non-uniform motion, 825.

Roberts, J. H., 666.

Salem, R., 39. Convexity theorems, 851.

Thrall, R. M., 706.

Tukey, J. W., 706.

Weyl, H., 262.

Whitehead, J. H. C. Combinatorial homotopy. I, 213.

Combinatorial homotopy. II, 453.

Woodbury, M. A., 706.

\section{INDEX OF RESEARCH PAPERS}

Abdelhay, J. On a theorem of representation, 408.

Albert, A. A. Absolute-valued algebraic algebras, 763, 1191.

Ankeny, N. C. A note on the minimum of a binary form, 615.

Baer, R., and Williams, C. Splitting criteria and extension types, 729.

${ }^{1}$ Where title of address is not given, the reference is to the Report of the Meeting at which the address was given. 
Bateman, P. T. Note on the coefficients of the cyclotomic polynomial, 1180.

Beckenbach, E. F., Gustin, W., and Shniad, H. On the mean modulus of an analytic function, 184.

Begle, E. G. A note on S-spaces, 577.

Bergman, S. An initial value problem for a class of equations of mixed type, 165.

Bing, R. H. A convex metric for a locally connected continuum, 812. Partitioning a set, 1101 .

Borel, A. Some remarks about Lie groups transitive on spheres and tori, 580.

Brauer, R. On a theorem of $H$. Cartan, 619.

Brunk, H. D. A consistency theorem, 204.

Bruynes, H., and Raisbeck, G. A method of analytic continuation suggested by heuristic principles, 193.

Cameron, R. H., and Hatfield, C. On the summability of certain orthogonal developments of nonlinear functionals, 130.

Campbell, R. C. $A$ simple solution of the diophantine equation $x^{3}+y^{3}=z^{2}+t^{2}, 442$.

Carmichael, R. D. Errata for On Euler's $\phi$ function, 212.

Chatland, H. On the Euclidean algorithm in quaratic number fields, 948.

Chatland, H., and Mann, H. B. Integral extensions of a ring, 592.

Cheng, T. T. The normal approximation to the Poisson distribution and a proof of a conjecture of Ramanujan, 396.

Civin, P. Approximation in Lip $(\alpha, p), 794$.

Cohn, R. M. A theorem on difference polynomials, 595.

- Inversive difference fields, 597.

Dekker, D. B. Hypergeodesic curvature and torsion, 1151.

Dietrich, V. E., and Rosenthal, A. Transcendence of factorial series with periodic coeffcients, 954.

Diliberto, S. P. Special properties of measure preserving transformations, 554.

Dilworth, R. P., and Ward, M. Note on a paper by C. E. Rickart, 1141.

Dowker, Y. N. A note on the ergodic theorems, 379.

Duffin, R. J. Nonlinear networks. III, 119.

Durfee, William H. See Jones, B. W.

Eckmann, B. Coverings and Betti numbers, 95.

Eckmann, B., Samelson, H., and Whitehead, G. W. On fibering spheres by toruses, 433.

Eilenberg, S. See Index of Addresses.

Ellis, D. Superposibility properties of naturally metrized groups, 639.

Erdös, P., Feller, W., and Pollard, H. A property of power series with positive coefficients, 201.

Feller, W. See Erdös, P.

Floyd, E. E. A nonhomogeneous minimal set, 957.

Fort, M. K. A note on equicontinuity, 1098.

Frank, E. Orthogonality properties of C-fractions, 384.

Frucht, R. On the groups of repeated graphs, 418.

Fullerton, R. E. Integral distances in Banach spaces, 901

Garabedian, P. R. A problem of Robinson, 917.

Gleason, A. M. Square roots in locally Euclidean groups, 446.

- A note on locally compact groups, 744.

Gonzallez, M. O. On the solution of ordinary differential equations of the first order invariant under contact transformations, 355.

Goodman, A. W. Note on regions omitted by univalent functions, 363.

Gustin. W. See Beckenbach, E. F.

Halmos, P. R. See Index of Addresses. 
Hatfield, C. See Cameron, R. H.

Herrera, F. E. On the equiconvergence of Fourier series and Fourier integrals, 1182.

Hewitt, E. A class of topological spaces, 421.

Hille, E. Remarks on a paper by Zeev Nehari, 552.

Hillman, A. On the reality of zeros of Bessel functions, 198.

Horn, A. Some generalizations of Helly's theorem on convex sets, 923.

Hsiung, C. C. Invariants of intersection of certain pairs of space curves, 623.

Hsü, H. Y. On Sonine's integral formula and its generalization, 370.

Jacobson, A. W. A generalized convolution for finite Fourier transformations, 804.

James, R. D. See Index of Addresses.

Jones, B. W. A theorem on integral symmetric matrices, 620.

Jones, B. W., and Durfee, William H. A theorem on quadratic forms over the ring of 2-adic integers, 758.

Jones, F. B. A note on homogeneous plane continua, 113.

Kac, M. See Index of Addresses.

Kelly, P. J. On Minkowski bodies of constant width, 1147.

Kosambi, D. D. The differential invariants of a two-index tensor, 90.

Kuo, H. T. A recurrence formula for $\zeta(2 n), 573$.

Leavitt, W., and Whaples, G. On matrices with elements in a principal ideal ring, 117.

Leighton, W., A substitute for the Picone formula, 325.

Loomis, L. H., and Whitney, H. An inequality related to the isoperimetric inequality, 961.

Lu, C. K. Classification of 2-manifolds with singular points, 1093.

Mann, H. B. See Chatland, H.

Mark, A. M. Some probability limit theorems, 885.

Mickle, E. J. On the extension of a transformation, 160.

Mirsky, L. On the frequency of pairs of square-free numbers with a given difference, 936.

Moise, E. E. A theorem on monotone interior transformations, 810.

- Grille decomposition and convexification theorems for compact metric locally connected continua, 1111.

Morse, M. L-S-homotopy classes on the topological image of a projective plane, 981.

Mostow, G. D. A new proof of E. Cartan's theorem on the topology of semi-simple groups, 969.

Motzkin, Th. Approximation by curves of a unisolvent family, 789.

The Euclidean algorithm, 1142.

Muhly, H. T. The irregularity of an algebraic surface and a theorem on regular surfaces, 940.

Myers, S. B. Spaces of continuous functions, 402.

Nachbin, L. On strictly minimal topological division rings, 1128.

Nagy, Gy. v. Sz. Über die Lage der Nullstellen eines Abstandspolynoms und seiner derivierten, 329.

Nehari, Z. The Schwarzian derivative and schlicht functions, 545.

Ostrom, T. G. The solution of linear integral equations by means of Wiener integrals, 343.

Parker, W. V. On the characteristic equations of certain matrices, 115.

Peixote, M. M. Generalized convex functions and second order differential inequalities, 563.

Pollard, H. See Erdös, P.

Rad6, T. On essentially absolutely continuous plane transfomations, 629.

Raisbeck, G. See Bruynes, H.

Ramaswami, V. On the number of positive integers less than $x$ and free of primedivisors greater than $x^{c}, 1122$. 
Ree, R. On a problem of Max A. Zorn, 575.

Reissner, E. See Index of Addresses.

Rosenbaum, J. See Rosenbaum, R. A.

Rosenbaum, R. A., and Rosenbaum, J. Some consequences of a well known theorem on conics, 933.

Rosenthal, A. See Dietrich, V. E.

Rosser, J. B. Real roots of Dirichlet L-series, 906.

Salem, R. See Index of Addresses.

Salzer, H. E., and Zucker, R. Table of the zeros and weight factors of the first fifteen Laguerre polynomials, 1004.

Samelson, H. See Eckmann, B.

Schafer, R. D. The Wedderburn principal theorem for alternative algebras, 604. Inner derivations of non-associative algebras, 769.

Scott, W. R. Some elementary topological properties of essential maximal model continua, 963.

Sewell, W. E. See Walsh, J. L.

Shapiro, H. N. Note on a theorem of Dickson, 450.

Sheffer, I. M. On the theory of sum-equations, 777.

Shniad, H. See Beckenbach, E. F.

Sholander, M. On the existence of the inverse operation in alternation groupoids, 746.

Spanier, E. H. The Mayer homology theory, 102.

Stark, R. H. On the representation of a function as a Hellinger integral, 155.

Stewart, B. M. A note on least common left multiples, 587.

Sumner, D. B. An inversion formula for the generalized Stieltjes transform, 174.

Taub, A. H. A characterization of conformally flat spaces, 85.

Thompson, F. B. A note on the unique factorization of abstract algebras, 1137.

Turán, P. On Descartes-Harriot's rule, 797.

Wall, H. S. Convergence of continued fractions in parabolic domains, 391.

Wallace, A. D. Cyclic invariance under multi-valued maps, 820.

Walsh, J. L., and Sewell, W. E. On interpolation to an analytic function in equidistant points: Problem $\beta, 1177$.

Ward, M. See Dilworth, R. P.

Weil, A. Numbers of solutions of equations in finite fields, 497.

Whaples, G. See Leavitt, W.

Whitehead, G. W. See Eckmann, B.

Whitehead, J. H. C. See Index of Addresses.

Whitney, H. See Loomis, L. H.

Wilansky, A. A necessary and sufficient condition that a summability method be stronger than convergence, 914.

Wilkins, J. E. An integration scheme of Maréchal, 191.

- $A$ bound for the mean value of a function, 801.

- Some remarks on ruled surfaces, 1169.

Williams, C. See Baer, R.

Wing, G. M. Summability with a governor of integral order, 146.

Wolfowitz, J. Remarks on the notion of recurrence, 394.

Wylie, C. R. The uniqueness of a certain line involution, 633.

Yang, C. T. A theorem in finite projective geometry, 930.

Young, G. S. On continuous curves irreducible about compact sets, 439.

Youngs, J. W. T. Remarks on cyclic additivity, 427.

Zucker, R. See Salzer, H. E. 